\title{
Recycled Lactobacillus pentosus biomass can regenerate biosurfactants after various fermentative and extractive cycles
}

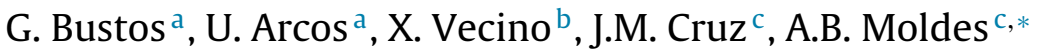 \\ a Unidad Académica Multidisciplinaria Mante, Área de Ingeniería Bioquímica Industrial, Universidad Autónoma de Tamaulipas, Blvd. E. C. González 1201 \\ Pte. Col. Jardín, 89840 Ciudad Mante, Tamaulipas, Mexico \\ ${ }^{\mathrm{b}}$ Chemical Engineering Department, Barcelona East School of Engineering (EEBE), Polytechnic University of Catalonia (UPC), Barcelona TECH, Barcelona \\ Research Center for Multiscale Science and Engineering, Campus Diagonal-Besòs, 08930 Barcelona, Spain \\ ${ }^{\mathrm{c}}$ Chemical Engineering Department, School of Industrial Engineering, Módulo Tecnológico Industrial (MTI), University of Vigo, Campus As \\ Lagoas-Marcosende, 36310 Vigo, Spain
}

\section{A R T I C L E I N F O}

\section{Article history:}

Received 19 October 2017

Received in revised form

22 December 2017

Accepted 19 January 2018

\section{Keywords:}

Probiotic lactic acid bacterium

Fermentation

Surface-active compounds

Colony forming units

Cell viability

\begin{abstract}
A B S T R A C T
In this work cells of Lactobacillus pentosus, growing on $20 \mathrm{~g} / \mathrm{L}$ of glucose for $15 \mathrm{~h}$ at $31^{\circ} \mathrm{C}$, were subjected to sequential fermentation and extraction processes with phosphate buffered saline (PBS) in order to study the capacity of $L$. pentosus to regenerate biosurfactants after various fermentative and extractive cycles. After a first extraction cycle, it was observed that, in absence of nutrients, $L$. pentosus, dissolved in PBS, does not have the capacity to induce the formation of new biosurfactants, although the extraction process almost did not affect the cell viability. However, when this biomass was recycled and subjected to three sequential fermentative processes, in presence of fresh fermentative medium, with their respective extraction procedures, $L$. pentosus cells recovered its capacity to produce more biosurfactants, observing an increase in the biosurfactant/biomass ratio, achieving a total biosurfactant concentration of $27 \mathrm{~g} / \mathrm{L}$ being the highest reported at the moment in the literature for L. pentosus.
\end{abstract}

(c) 2018 Elsevier B.V. All rights reserved.

\section{Introduction}

Lactobacillus pentosus is a probiotic lactic acid bacterium that is able to produce cell-bound biosurfactants, which was identified in previous works as a glycolipopeptide, composed by $10 \%$ carbohydrates, $30 \%$ proteins and $60 \%$ lipids. The major fractions of this biosurfactant are composed by lipids and proteins, being the fatty acid chain constituted by linoelaidic acid (C18:2), oleic or elaidic acid (C18:1), palmitic acid (C16) and stearic acid (C18) [1]. Concerning the uses of this biosurfactant, it has been proved as foaming agent in froth flotation processes [2] as well as in the bioremediation of hydrocarbon-contaminated sites [3-5].

Moreover, $L$. pentosus is an interesting strain, from an environmental point of view, because it has the ability to ferment pentoses [6], hence it can be used for the valorization of secondary raw material, based on lignocellulosic residues, composed by hemicellulosic sugars. Therefore, Bustos et al. [7] have proposed the use of hemicellulosic liquors ( $18 \mathrm{~g} / \mathrm{L}$ of xylose, $11.1 \mathrm{~g} / \mathrm{L}$ of glucose, $4.3 \mathrm{~g} / \mathrm{L}$ of arabinose and $4 \mathrm{~g} / \mathrm{L}$ of acetic acid), obtained from vineyard pruning waste, for the production of lactic acid and biosurfactants

\footnotetext{
* Corresponding author.

E-mail address: amoldes@uvigo.es (A.B. Moldes).
}

using L. pentosus. Additionally, Moldes et al. [8] have evaluated the use of hemicellulosic sugars, obtained from barley bran husks, corn cobs, vineyard pruning waste, and eucalyptus globulus chips, containing between $16.6 \mathrm{~g} / \mathrm{L}$ and $40.7 \mathrm{~g} / \mathrm{L}$ of xylose, to produce biosurfactants using $L$. pentosus; achieving maxima concentrations of biosurfactants between $2.9 \mathrm{~g} / \mathrm{L}-6.5 \mathrm{~g} / \mathrm{L}$, depending of the secondary raw material used to obtain the hemicellulosic sugars. Moreover, Rivera et al. [9] also have evaluated the capacity of $L$. pentosus to produce biosurfactants from hemicellulosic sugars coming from distilled grape marc. In these circumstances, L. pentosus produced $4.8 \mathrm{mg} / \mathrm{L}$ of cell-bound biosurfactants, measured as surfactin equivalents.

Concerning the fermentation of hexoses, Rodrigues et al. [10] have produced biosurfactants from $L$. pentosus using MRS broth (Man, Rogosa \& Sharpe medium for lactobacilli strains) as culture medium, obtaining maximum biosurfactant concentrations of $1.7 \mathrm{~g} / \mathrm{L}$.

As it can be observed, the amount of cell-bound biosurfactants produced in each batch is very low in comparison with other metabolites produced by biotechnological processes. Hence, it is necessary to design biotechnological processes that allow to obtain higher concentrations of cell-bound biosurfactants, otherwise their industrial applications will be very restrictive. For instance, Khondee et al. [11] have proposed the immobilization 
of Bacillus sp GY19 in chitosan beads to increase cell density and facilitate the production of a lipopeptide biosurfactant achieving a maximum concentration between 9.8 and $10.9 \mathrm{~g} / \mathrm{L}$. However, this technology only can be applied for the biosurfactants produced extracellularly.

The aim of this work was evaluate the recycle of $L$. pentosus cells, during various fermentative and extractive processes, in order to study its viability and increase the productivities and concentrations of the cell-bound biosurfactants produced by this probiotic lactic acid bacterium.

\section{Materials and methods}

\subsection{Microorganism}

Lactobacillus pentosus CECT-4023T (ATCC-8041) was obtained from the Spanish Type Culture Collection (CECT) (Valencia, Spain). Prior to the fermentation processes the lyophilized strain was dissolved, in the specific medium for lactobacilli strains, MRS broth and growth for $24 \mathrm{~h}$ at $31^{\circ} \mathrm{C}$, following the protocol established by the CECT. Inoculum was prepared by growing cells, for $48 \mathrm{~h}$ at $31^{\circ} \mathrm{C}$, in Petri dishes, containing the specific MRS agar. Following, cells from plates were solubilized with $5 \mathrm{~mL}$ of culture media.

\subsection{Fermentation process}

Fermentations were carried out in $250 \mathrm{~mL}$ Erlenmeyer flask with a working volume of $100 \mathrm{~mL}$ [9,10]. The fermentation medium consisted of MRS broth containing $20 \mathrm{~g} / \mathrm{L}$ of glucose. Fermentations were carried out at $31^{\circ} \mathrm{C}$ for $15 \mathrm{~h}$ and $150 \mathrm{rpm}$. The amount of inoculum employed in all the fermentations was $5 \%(\mathrm{v} / \mathrm{v})$.

\subsection{Extraction of L. pentosus biosurfactants}

In order to obtain the cell-bound biosurfactant extract, once finished each fermentation process, L. pentosus cells were filtered, washed two times with distilled water, and re-suspended in $20 \mathrm{~mL}$ of phosphate buffered saline (PBS) $\left(10 \mathrm{mM} \mathrm{KH} \mathrm{HO}_{4} / \mathrm{K}_{2} \mathrm{HPO}_{4}\right.$ with $150 \mathrm{mM} \mathrm{NaCl}$ ). The extraction was carried at room temperature $\left(25^{\circ} \mathrm{C}\right)$ during $2 \mathrm{~h}$ at $150 \mathrm{rpm}$. Following, the biomass was separated from the PBS solution, containing the biosurfactants by centrifugation at $5000 \mathrm{rpm}$ and $-4{ }^{\circ} \mathrm{C}$ during $15 \mathrm{~min}[3,5]$.

Afterwards, the solutions, containing the cell-bound biosurfactant extract, were dialyzed against demineralized water at $4{ }^{\circ} \mathrm{C}$ in a Cellu-Sep@ membrane (molecular weight cut-off 6000-8000 Da; Membrane Filtration Products, Inc., USA) for $48 \mathrm{~h}$, and finally the biosurfactant extracts were lyophilized using a lyophilizer Telstar LyoQuest (Spain).

On the other hand, in order to evaluate if all the biosurfactants were extracted from cells, the biomass, containing $L$. pentosus cells, was subjected sequentially to new extractive processess until no biosurfactants were detected in the PBS. After each extractive process the viability of cells was quantified by counting the colony forming units (CFU).

Alternatively, the biomass of $L$. pentosus was recycled, starting a new fermentative and extractive process. After each cycle, the amount of biosurfactant and biomass produced was quantified. One cycle corresponds with a $15 \mathrm{~h}$ fermentative process followed by $2 \mathrm{~h}$ of extractive process with PBS. Before the biosurfactant extraction it is necessary to centrifuge and wash the biomass with distilled water, in order to remove the components of fermentation medium. Therefore, after each fermentation, biomass was washed and subjected to an extraction process with PBS, and following biomass was introduced in fresh MRS broth, containing $20 \mathrm{~g} / \mathrm{L}$ of glucose. All the extraction processes were carried out under sterilized conditions in a laminar flow biosafety cabinet (Bio-II-A, Telstar).
In total 3 consecutive cycles were carried out recycling all the biomass obtained after each cycle. Two different sets of experiments, with their corresponding cycles were established: in one set it was used regular biomass (RB) subjected to one extraction process, whereas in the other set of experiments, before recycling, biomass was subjected to a complete extraction of biosurfactants by 3 consecutive extraction processes. This biomass was named exhausted biomass (EB).

\subsection{Quantification and characterization of biosurfactants}

Biosurfactant in PBS was quantified based on the surface tension (ST) value of the extract. Under the critical micellar concentration (CMC) it can be established a linear relationship between the increase in the ST and the concentration of a specific biosurfactant in an aqueous solution. Thus, for establishing this relationship, solutions in PBS, with different concentrations of this biosurfactant extract, were prepared, and filtered with cellulose filter paper (45 $\mu \mathrm{m}$, Tros Anoia, Spain). Finally, the ST was measured using a tensiometer KRÜSS (K20 EasyDyne), choosing the Wilhelmy plate method. Measurements were made in triplicate samples to confirm the reproducibility of surface tension measurements. The reference surface tension value of PBS without biosurfactant was $72 \mathrm{mN} / \mathrm{m}$.

Additionally, biosurfactant extract was subjected to FTIR analysis using a Niocolet 6700 FTIR spectrometer (Thermo Scientific) by applying the protocol employed in previous works [1].

\subsection{Quantification of cell viability}

Colony forming units ( $\mathrm{CFU}$ ) were the units used to estimate the number of viable L. pentosus cells, after the extraction of cell-bound biosurfactants. Therefore, $1 \mathrm{~mL}$ of fermentation medium, containing the L. pentous cells, before and after extraction of biosurfactants, were diluted several times up to $10^{-9}$ and plated in MRS agar for obtaining an acceptable number of counting colonies. Then, plates were incubated for $48 \mathrm{~h}$ at $31^{\circ} \mathrm{C}$. Concentrations of CFU were expressed using logarithmic notation, where the value shown is the base 10 logarithm of the concentration.

\subsection{Biomass quantification}

Biomass was quantified by determining the optical density of the fermentation medium at $600 \mathrm{~nm}$. The absorbance was measured with a double beam spectrophotometer (Jasco V-650, Spain).

Fermented medium $(5 \mathrm{~mL})$ was centrifuged to obtain the biomass, which was washed twice with distilled water and dried at $105^{\circ} \mathrm{C}$ for $48 \mathrm{~h}$ before weighing. Following a calibration curve, involving absorbance values at $600 \mathrm{~nm}$ and different biomass concentrations, was established.

\subsection{Colorimetric analysis}

The color of aqueous solutions containing the biosurfactant extracted from $L$. pentosus was evaluated with a double beam spectrophotometer (Jasco V-650, Spain). Samples were filtered through a membrane of $0.45 \mu \mathrm{m}$ pore size before analysis.

The CIELAB color system is widely accepted by both the scientific community and industry, since is the most 'perceptually uniform' of the color spaces $[12,13]$. The CIELAB color system is organized with three axes in a spherical form: $L^{*}, a^{*}$, and $b^{*}$. A convenient way of visually representing tristimulus values is the use of chromaticity co-ordinates, which maps all colors into a two-dimensional space, called CIE chromaticity diagram. This space has two axes $\mathrm{x}$ and $\mathrm{y}$. The CIE chromaticity diagram provides a color map on which the chromaticities of all colors are plotted [14,15]. 


\section{Results and discussion}

\subsection{Characterization of biosurfactant}

L. pentosus was able to produce a cell-bound biosurfactant that reduces the surface tension of distilled water up to $50 \pm 3 \mathrm{mN} / \mathrm{m}$ with a CMC about $1.95 \mathrm{~g} / \mathrm{L}$. Velraeds et al. [16] studied the different capacities and CMC values of biosurfactants, produced by lactic acid strains, observing CMC values between 1 and $3 \mathrm{~g} / \mathrm{L}$ with similar capacities to reduce the ST than the biosurfactant produced by $L$. pentosus.

a)

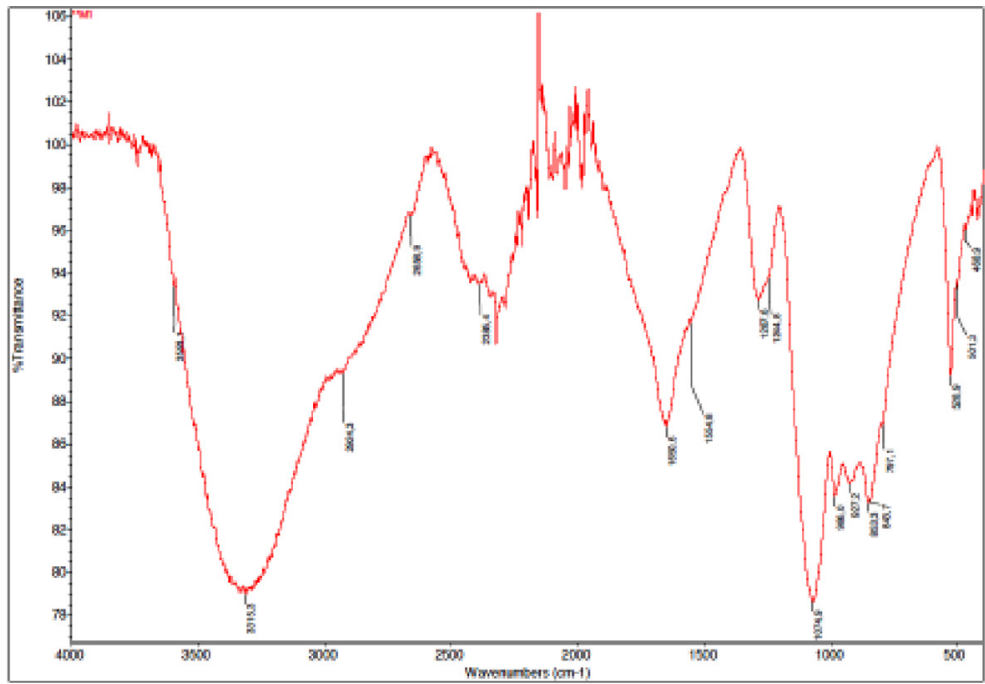

b)

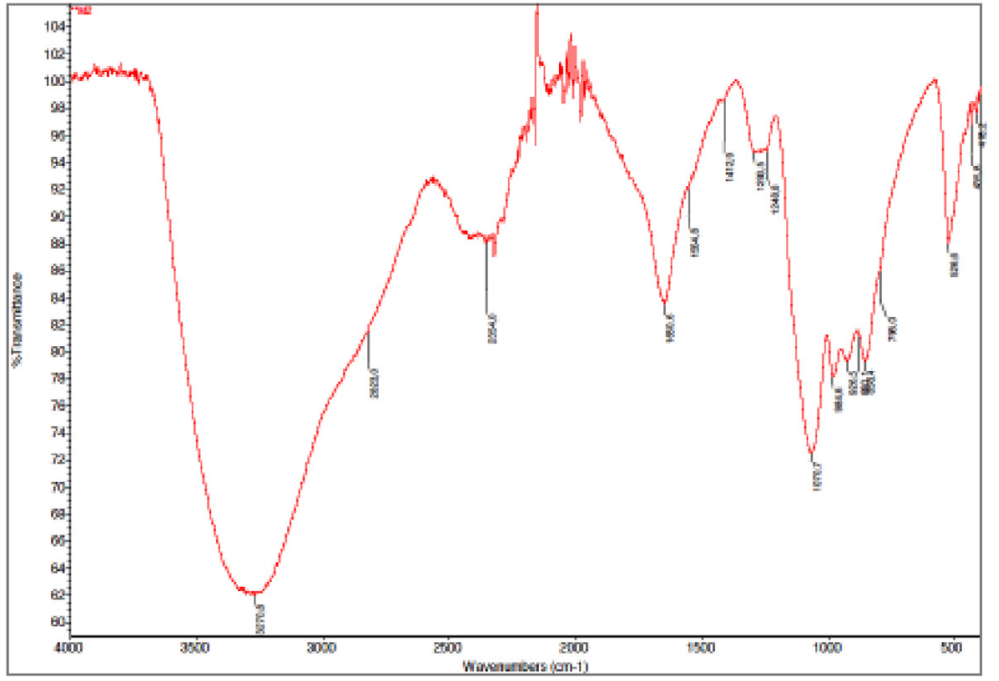

c)

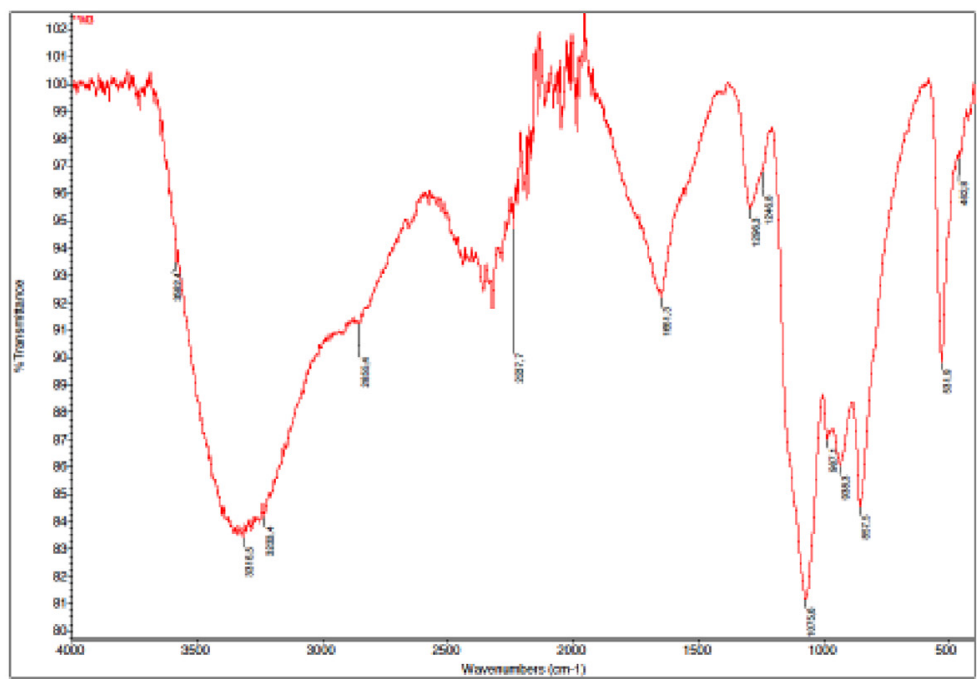

\section{d)}

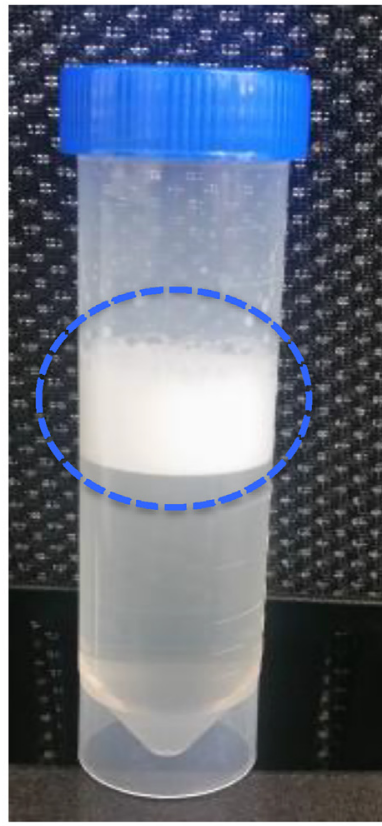

Fig. 1. FTIR of the biosurfactant extract after a) $1^{\circ}$, b) $2^{\circ}$ and c) $3^{\circ}$ extraction and d) picture of the biosurfactant, in aqueous solution, with foam formation. 
Eq. (1) shows the relationship between the surface tension of an aqueous solution, at different concentrations of biosurfactant produced by L. pentosus.

$\mathrm{ST}=(-8.7194 \times \mathrm{S})+69.544$

where ST is the surface tension of aqueous solution $(\mathrm{mN} / \mathrm{m})$ and $\mathrm{S}(\mathrm{g} / \mathrm{L})$ is the biosurfactant concentration. This equation only can be used when the biosurfactant is under its CMC and it allows to convert surface tension values into concentration of biosurfactant, with a correlation coefficient value $\left(\mathrm{r}^{2}\right)$ of 0.857 .

Fig. 1 shows a biosurfactant solution containing $5.4 \mathrm{~g} / \mathrm{L}$ of biosurfactant, observing the presence of foam after stirring, as well as the FTIR chromatograms for the biosurfactant obtained after various extractive cycles. It was observed that there are no differences between them and they are similar to the FTIR of other cell-bound biosurfactant extracts produced by lactic acid bacteria reported in previous works [1]. It can be speculated that this biosurfactant has a hydrophilic-lipophilic balance (HLB) $>$ than 10 , because it can act as a detergent [17], with notable formation of foam and it is able to stabilize oil in water $(\mathrm{O} / \mathrm{W})$ emulsions as it was observed in a previous work [1], where this biosurfactant was able to stabilize $\mathrm{O} / \mathrm{W}$ emulsions containing rosemary oil.

On the other hand, aqueous solutions of this biosurfactant seem to have colorimetric properties compatible, with industrial applications, for instance in the cosmetic and pharmaceutical industries; although the best way to evaluate these properties is through a colorimetric analysis. Table $1 \mathrm{~S}$ (see the Supplementary material) includes the color parameters obtained with the CIELAB and Tristimulus color systems. It can be observed that $\mathrm{L}^{*}$ values, that measure the lightness of the samples, are about 100 indicating that the solutions containing biosurfactant extracts are almost white, this fact was corroborated by the values of $\mathrm{x}$ and $\mathrm{y}$, around 0.3 , for both variables, indicative of the white color in the Tristimulus system. Those samples with higher amount of biosurfactant gave higher $\mathrm{L}^{*}$ values.

\subsection{Production of biosurfactants from L. pentosus by biomass recycling}

The studies dealing with the production of cell-bound biosurfactants are scarce in the literature in comparison with extracellular biosurfactants and none of these works have contemplated the recycling of biomass, once the biosurfactants were extracted. In this work, a biosurfactant was produced by $L$. pentosus using a rich medium, MRS broth, during $15 \mathrm{~h}$, and following the biomass of $L$. pentosus was separated from the culture broth, washed with distilled water, and subjected to PBS extraction, in order to obtain the biosurfactant extract in the supernatant, under sterile conditions. Finally, biosurfactant was lyophilized and quantified, evaluating the viability of cells previously to recycling the biomass.

After a first extraction $89.6 \%$ of biosurfactant was obtained, whereas the rest, $10.4 \%$, was released after a second extraction process. A third extraction step gave absence of biosurfactant (see Fig. $1 S$ in the Supplementary material).

In absence of nutrients, L. pentosus does not have the ability to induce the production of biosurfactants, deduced by the absence of biosurfactants when biomass is just dissolved in PBS. Regarding the viability of $L$. pentosus cells, the experiments carried out showed that the extraction with PBS is compatible with maintaining the viability of $L$. pentosus cells (Fig. 2a), observing after the $1^{\circ}$ extraction cycle a cell viability of $1.3 \times 10^{8} \mathrm{CFU} / \mathrm{mL}$, which was kept after a $3^{\circ}$ extraction process $\left(1.2 \times 10^{8} \mathrm{CFU} / \mathrm{mL}\right)$ (see also Fig. $2 \mathrm{~S}$ in the Supplementary material, showing pictures of colonies). These results are in agreement with those obtained by Portilla et al. [18]. In that work, it was observed that Lactobacillus acidophilus cells

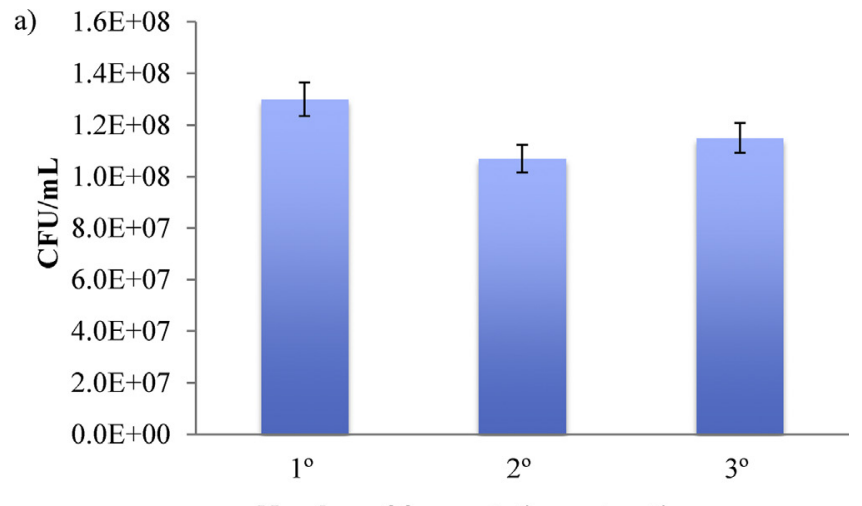

Number of fermentation-extraction process

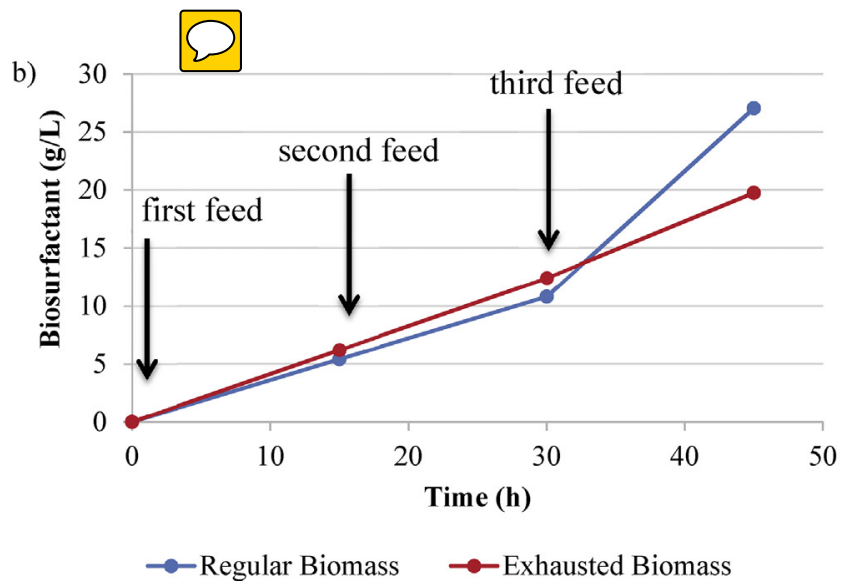

Fig. 2. a) Cell viability of $L$. pentosus biomass after various fermentative and extractive processes. b) Kinetic of biosurfactant production during sequential fermentation and extraction processes using regular and exhausted biomass respectively.

showed no difference in viability before or after PBS extraction of biosurfactants, achieving values of $0.9 \times 10^{9} \mathrm{CFU} / \mathrm{mL}$ in both cases.

Therefore, various fermentative and extractive cycles were carried out in order to elucidate if the consecutive extraction of biosurfactants can induce or restrict the production of biosurfactants by $L$. pentosus. In this operational system biosurfactants were extracted from cells under sterile conditions and following biomass was subjected to a new fermentative cycle with fresh glucose and nutrients.

Additionally, three consecutive fermentative and extractive processes were carried using the biomass already subjected to three consecutive extraction processes (Fig. 2b). This biomass gave $6.2 \mathrm{~g} / \mathrm{L}$ of biosurfactants, after a new fermentative process, whereas biomass subjected to a single extraction step, gave $5.4 \mathrm{~g} / \mathrm{L}$ of biosurfactants. The concentration of biomass obtained, after $15 \mathrm{~h}$, for $L$. pentosus is in concordance with the data provided by other authors [19].

Fig. 2b also shows a comparative study between two consecutive fermentations and extraction processes, containing three fermentation-extraction cycles, using regular or exhausted biomass. After each extractive process biomass was fed to a new fermentation medium containing $20 \mathrm{~g} / \mathrm{L}$ of glucose and fresh nutrients. Three feed processes were carried out, obtaining after $45 \mathrm{~h}$ of fermentation, $27 \mathrm{~g} / \mathrm{L}$ of biosurfactant extract, using the regular biomass (RB) or $19.7 \mathrm{~g} / \mathrm{L}$ employing exhausted biomass (EB).

The amount of biomass increased slightly after the $3^{\circ}$ consecutive fermentative-extractive processes. The yield biosurfactant/biomass ratio $(\mathrm{g} / \mathrm{g})$ obtained after the first feeding was $3.1 \mathrm{~g} / \mathrm{g}$ and $3.0 \mathrm{~g} / \mathrm{g}$ for RB and EB respectively; whereas after three cycles of feeding this value increased up to $7.5 \mathrm{~g} / \mathrm{g}$ and $5.2 \mathrm{~g} / \mathrm{g}$ 
respectively, observing a restriction of biosurfactant production when the biomass used was subjected to a complete extraction of biosurfactants. However, it is clear that the recycling of biomass allows to obtain higher biosurfactant yields (see Table $2 \mathrm{~S}$ in the Supplementary material).

It can be speculated that $L$. pentosus achieved a stationary phase because the concentration of biomass was almost the same after each sequential fermentative-extractive process, however the concentration of biosurfactant, increased, producing higher biosurfactant/biomass yields after each sequential fermentativeextractive process.

Substrate concentration, at a minimal level, allowed optima microbial growth without catabolite repression or substrate inhibition, and substrate was utilized for biosurfactant production rather than biomass formation. It is known that most of the microorganisms can undergo substrate and product inhibition, thus the sequential addition of substrate could improve the yields of fermentative processes avoiding the presence of high substrate concentrations. On the other hand, many microorganisms suffer from product inhibition; therefore, the sequential extraction of fermentative products can avoid the product inhibition, improving the yield of fermentative products.

\section{Conclusions}

This is the first work where it is demonstrated that the biomass of lactobacilli cells can be recycled after extracting the biosurfactants, bounded to their plasmatic membrane, increasing the productivities and yields achieved in regular fermentative processes. Additionally, it was observed that the cell viability of $L$. pentosus almost has not been affected by the extractive process of biosurfactants and after extraction cells recovered their capacity to produce fresh surface-active compounds.

\section{Acknowledgments}

G. Bustos-Vázquez acknowledges to the CONACyT (Call 2015) for the financial support of sabbatical stays abroad for developing this work. Authors thank the Spanish Ministry of Economy and Competitiveness (MINECO) for funding the research project CTM2015-68904-R and X. Vecino through a Juan de la Cierva contract (FJCI-2014-19732). Also, this study was supported by the Xunta de Galicia under project ED431B 2017/77.

\section{Appendix A. Supplementary data}

Supplementary data associated with this article can be found, in the online version, at https://doi.org/10.1016/j.bej.2018.01.021.

\section{References}

[1] X. Vecino, L. Barbosa-Pereira, R. Devesa-Rey, J.M. Cruz, A.B. Moldes, Optimization of extraction conditions and fatty acid characterization of Lactobacillus pentosus cell-bound biosurfactant/bioemulsifier, J. Sci. Food Agric. 95 (2015) 313-320.

[2] X. Vecino, R. Devesa-Rey, J.M. Cruz, A.B. Moldes, Evaluation of biosurfactant obtained from Lactobacillus pentosus as foaming agent in froth flotation, J. Environ. Manage. 128 (2013) 655-660.

[3] O. Portilla-Rivera, A. Torrado, J.M. Domínguez, A.B. Moldes, Stability and emulsifying capacity of biosurfactants obtained from lignocellulosic sources using Lactobacillus pentosus, J. Agric. Food Chem. 56 (2008) 8074-8080.

[4] A.B. Moldes, R. Paradelo, D. Rubinos, R. Devesa-Rey, J.M. Cruz, Ex situ treatment of hydrocarbon-contaminated soil using biosurfactants from Lactobacillus pentosus, J. Agric. Food Chem. 59 (2011) 9443-9447.

[5] A.B. Moldes, R. Paradelo, X. Vecino, J.M. Cruz, E. Gudiña, L. Rodrigues, J.A Teixeira, J.M. Domínguez, M.T. Barral, Partial characterization of biosurfactant from Lactobacillus pentosus and comparison with sodium dodecyl sulphate for the bioremediation of hydrocarbon contaminated soil, BioMed. Res. Int. (2013), 961842.

[6] A.B. Moldes, X. Vecino, J.M. Cruz, Nutraceuticals and food additives, in: A. Pandey, M.A. Sanromán, G. Du, C.R. Soccol, C.G. Dussap (Eds.), Current Developments in Biotechnology and Bioengineering Food and Beverages Industry, Elsevier, 2016, pp. 143-158.

[7] G. Bustos, N. de la Torre, A.B. Moldes, J.M. Cruz, J.M. Domínguez, Revalorization of hemicellulosic trimming vine shoots hydrolyzates trough continuous production of lactic acid and biosurfactants by L. pentosus, J. Food Eng. 78 (2007) 405-412.

[8] A.B. Moldes, A.M. Torrado, M.T. Barral, J.M. Domínguez, Evaluation of biosurfactant production from various agricultural residues by Lactobacillus pentosus, J. Agric. Food Chem. 55 (2007) 4481-4486.

[9] O.M.P. Rivera, A.B. Moldes, A.M. Torrado, J.M. Domínguez, Lactic acid and biosurfactants production from hydrolyzed distilled grape marc, Process Biochem. 42 (2007) 1010-1020.

[10] L. Rodrigues, A. Moldes, J. Teixeira, R. Oliveira, Kinetic study of fermentative biosurfactant production by Lactobacillus strains, Biochem. Eng. J. 28 (2006) 109-116.

[11] N. Khondee, S. Tathong, O. Pinyakong, R. Müller, S. Soonglerdsongpha, C. Ruangchainikom, C. Tongcumpou, E. Luepromchai, Lipopeptide biosurfactant production by chitosan-immobilized Bacillus sp. GY19 and their recovery by foam fractionation, Biochem. Eng. J. 93 (2015) 47-54.

[12] R.S. Berns, Billmeyer and Saltzman's Principles of Color Technology, 3rd ed., John Wiley \& Sons, New York, 2000.

[13] H.G. Völz, Industrial Color Testing, Wiley-VCH, Weinheim, 2001

[14] X. Vecino, R. Devesa-Rey, A.B. Moldes, J.M. Cruz, Optimization of batch operating conditions for the decolourization of vinasses using surface response methodology, Microchem. J. 102 (2012) 83-90.

[15] M. Perez-Ameneiro, X. Vecino, L. Barbosa-Pereira, J.M. Cruz, A.B. Moldes, Removal of pigments from aqueous solution by a calcium alginate-grape marc biopolymer: a kinetic study, Carbohyd. Polym. 101 (2014) 954-960.

[16] M.M.C. Velraeds, H.C. Van Der Mei, G. Reid, H.J. Busscher, Physicochemical and biochemical characterization of biosurfactants released by Lactobacillus strains, Colloid Surf. B 8 (1996) 51-61.

[17] X. Vecino, J.M. Cruz, A.B. Moldes, L.R. Rodrigues, Biosurfactants in cosmetic formulations: trends and challenges, Crit. Rev. Biotechnol. 37 (2017) 911-923.

[18] O.M. Portilla, B. Rivas, A. Torrado, A.B. Moldes, J.M. Domínguez, Revalorisation of vine trimming wastes using Lactobacillus acidophilus and Debaryomyces hansenii, J. Sci. Food Agric. 88 (2008) 2298-2308.

[19] O.M. Portilla-Rivera, G. Arzate Martínez, L. Jarquín Enríquez, P.A. Vázquez Landaverde, J.M. Domínguez González, Lactic acid and biosurfactants production from residual cellulose films, Appl. Biochem. Biotechnol. 177 (2015) 1099-1114. 